\title{
The Impact of Job Burnout towards Job Performance among Nurses
}

\author{
Dayang Nailul Munna Abang Abdullah \\ Faculty of Business Management \\ Universiti Teknologi MARA \\ 40450 Shah Alam, Selangor, Malaysia \\ nailul@salam.uitm.edu.my
}

\author{
Fong Chui Yuen \\ Faculty of Cognitive Sciences \& Human Developemnt \\ Universiti Malaysia Sarawak \\ 94300 Kota Samarahan, Sarawak, Malaysia \\ cy cb18@hotmail.com
}

\begin{abstract}
The aim of this study was to determine the relationship between job burnout and job performance among nurses. The factors of interest in this study were components of job burnout, which included emotional exhaustion, depersonalization, and diminished personal accomplishment; and job performance of nurses. Survey questionnaire was used to collect the data needed for analysis, which was adapted and modified from Maslach Burnout Inventory (MBI). The respondents were nurses from the private hospital at Perak. Data collected was analyzed using SPSS version 12.0 for Window, and the methods of analysis were Pearson correlation and multiple regression analysis. The findings of this study revealed that there were significant correlations between emotional exhaustion $(r=0.305, p=0.006)$, depersonalization $(\mathrm{r}=\mathbf{0 . 2 3 9}, \mathrm{p}=\mathbf{0 . 0 3 1})$ and job performance. Meanwhile, this study failed to establish a relationship between diminished personal accomplishment and job performance. On the other hand, multiple regression analysis showed that emotional exhaustion was the dominant factor that affecting job performance $(\beta=0.305, \quad r 2=0.093)$. In conclusion, nursing profession is at high risk of job burnout or particularly emotional exhaustion, which will jeopardize nurses' job performance and eventually contribute to deterioration in quality of care.
\end{abstract}

Keywords-job burnout; emotional exhaustion; depersonalization; diminished personal accomplishment; job performance.

\section{INTRODUCTION}

Burnout is a syndrome of emotional exhaustion and cynicism that occurs frequently among individuals who do 'people-work' of some kind and are required to interact intensively with client and coworkers on regular basis, which the interaction, filled with feelings of anger, embarrassment, fear or despair, are centered on client's current problem in terms of psychological, social, and/or physical a prolonged exposure to these stressors could lead to job burnout among helping professions [1].

Occupations that required intensive interaction are more prone to experience emotional exhaustion and cynicism, or experiencing burnout, a term developed to describe such individuals [1]. Nurses who also known as the "angels of mercy" worked to help patients are exposed to high risk of getting burnout, because nurses faced high demand from patients, their family and co-workers in daily job and they are working with intense interaction with others. Nurses faced multiple demands on their time and energy at daily basis [2]. Persons who continually work with people under high demand of physical and emotion such as pity, sympathy, and compassion find that the constant stress can be emotionally draining and can cause burnout [3]

The researches done by Lee and Ashforth $(1993,1996)$ and Cordes and Dougherty (1993) claimed that burnout is negatively related to the levels of job performance [4]. Employees who are emotionally exhausted will tend to withdraw from the organization in the forms of absenteeism, physical isolation, extended break and avoids contact with organizational members and clients [4]. All of the aforementioned withdrawal behaviors will directly lead to reduced level of performance of nurses [5]. When it happened in the healthcare institutes, emotional exhausted nurses will try to avoid being close to patients as well as their coworkers, and they will be unable to understand the situation or problems of the patients, leaving patients in the suffers, without being able to help. When a nurse failed to help his/her patients to solve problems, his/her job performance is considered as diminished.

In the health care industry, the consequences of burnout would be very costly. When a nurse get burned-out, she is emotionally exhausted, depersonalized, and has reduced personal accomplishment [1]. In other words, she wouldn't feel excited by her job, then she tried to emotionally withdrawal from her patients and co-workers, at the end, developed low self-worth and less valued her job. A nurse who has been burned-out is expected to have reduced job performance, which will be reflected on nurse's absenteeism rate, job turnover, and low morale [1]. Thus, the consequences of burnout, will lead to deterioration in the quality of care or service that patients receive by "interfering with the nurses ability to meet workload demands and provide consistent patient care" [5].

The objective of this study was to investigate the relationship of job burnout factors namely emotional exhaustion, depersonalization, reduced personal accomplishment, and job performance among nurses in private hospitals.

\section{LITERATURE REVIEW}

\section{A. Burnout among Nurses}

Nurses are suggested to be vulnerable to burnout [6]. As pointed out in the research done by Fray-Toft and Anderson 